\title{
Improving Sensitivity of Electrochemical Sensors with Convective Transport in Free-Standing, Carbon Nanotube Structures
}

\author{
Benjamin J. Brownlee \\ Brigham Young University - Provo \\ Kevin M. Marr \\ Brigham Young University - Provo \\ Jonathan C. Claussen \\ Brigham Young University - Provo \\ Brian D. Iverson \\ Brigham Young University - Provo, bdiverson@byu.edu \\ Follow this and additional works at: https://scholarsarchive.byu.edu/facpub \\ Part of the Mechanical Engineering Commons
}

\section{Original Publication Citation}

Brownlee, B. J., Marr, K. M., Claussen, J. C., and Iverson, B. D., 2017, "Improving sensitivity of electrochemical sensors with convective transport in free-standing, carbon nanotube structures," Sensors and Actuators B: Chemical, Vol. 246, pp. 20-28. DOI:10.1016/ j.snb.2017.02.037

\section{BYU ScholarsArchive Citation}

Brownlee, Benjamin J.; Marr, Kevin M.; Claussen, Jonathan C.; and Iverson, Brian D., "Improving Sensitivity of Electrochemical Sensors with Convective Transport in Free-Standing, Carbon Nanotube Structures" (2017). Faculty Publications. 1818.

https://scholarsarchive.byu.edu/facpub/1818

This Peer-Reviewed Article is brought to you for free and open access by BYU ScholarsArchive. It has been accepted for inclusion in Faculty Publications by an authorized administrator of BYU ScholarsArchive. For more information, please contact ellen_amatangelo@byu.edu. 


\title{
Improving Sensitivity of Electrochemical Sensors with Convective Transport in Free-Standing, Carbon Nanotube Structures
}

\author{
Benjamin J. Brownlee, ${ }^{1}$ Kevin M. Marr, ${ }^{1}$ Jonathan C. Claussen, ${ }^{2}$ Brian D. Iverson ${ }^{1 *}$ \\ *Corresponding author email: bdiverson@byu.edu
}

\begin{abstract}
High-aspect-ratio, porous membrane of vertically-aligned carbon nanotubes (CNTs) were developed through a templated microfabrication approach for electrochemical sensing. Nanostructured platinum (Pt) catalyst was deposited onto the CNTs with a facile, electroless deposition method, resulting in a Pt-nanowire-coated, CNT sensor (PN-CNT). Convective mass transfer enhancement was shown to improve PN-CNT sensor performance in the non-enzymatic, amperometric sensing of hydrogen peroxide $\left(\mathrm{H}_{2} \mathrm{O}_{2}\right)$. In particular, convective enhancement was achieved through the use of high surface area to fluid volume structures and concentration boundary layer confinement in a channel. Stir speed and sensor orientation especially influenced the measured current in stirred environments for sensors with through-channel diameters of $16 \mu \mathrm{m}$. Through-flow sensing produced drastically higher signals than stirred sensing with over $90 \%$ of the $\mathrm{H}_{2} \mathrm{O}_{2}$ being oxidized as it passed through the PN-CNT sensor, even for low concentrations in the range of $50 \mathrm{nM}$ to $500 \mu \mathrm{M}$. This effective utilization of the analyte in detection demonstrates the utility of exploiting convection in electrochemical sensing. For through-flow at $100 \mu \mathrm{L} \mathrm{s}^{-1}$, a sensitivity of $24,300 \mu \mathrm{AmM}^{-1} \mathrm{~cm}^{-2}$ was achieved based on the frontal projected area $\left(871 \mu \mathrm{AmM}^{-}\right.$ ${ }^{1} \mathrm{~cm}^{-2}$ based on the nominal microchannel surface area), with a $0.03 \mu \mathrm{M}$ limit of detection and a linear sensing range of $0.03-500 \mu \mathrm{M}$.
\end{abstract}

Keywords: electrochemical, amperometric sensing, carbon nanotube, platinum, microfluidics, convection

1 Department of Mechanical Engineering, Brigham Young University, 435 Crabtree, Provo, UT, 84602

2 Department of Mechanical Engineering, Iowa State University, 2624F Howe Hall, Ames, IA, 50011 


\section{Introduction}

Transport in chemical reactions can play a critical role in introducing reactants to or removing products from the surface where the reaction takes place. In fact, mass transport is cited as having a major influence on the performance of many chemical technologies, including chemical reactors [1-3], lithium-oxygen batteries [4], and fuel cells [5]. In sensor applications where the target analyte may occur in low concentrations, transport of the analyte to the reacting surface can be the primary limitation of the sensor approach (i.e. "transport-limited" sensors). With the prominent reduction in feature sizes and corresponding reduction in sensing surface area available with microelectromechanical systems, some sensor platforms can suffer from a significant limitation in mass transfer rates to the sensing surface (e.g. micro-cantilevers). In cases where the analyte concentration is low, transport must be efficient to capitalize on the sparsely available target. Increasing the flow rate, increasing the surface area, and/or limiting growth of the concentration boundary layer are techniques that can be exploited to increase the convective transport of the analyte. This work demonstrates an effective platform to increase convective transport with applications in chemical sensing.

Enhancement of the analyte introduction rate can be achieved by increasing the flow rate of the analyte in solution. As the motion of the analyte is increased, the probability of analyte reaching a reacting surface increases and results in an overall increase in introduction rate. A good example of increased analyte flow is the rotating disk electrode, where the introduction rate of analyte to the surface increases as the rotation rate increases [6]. Several recent studies have also investigated catalytic structures which move through the analyte solution [7-12], thereby increasing the apparent analyte flow and enhancing the chemical introduction rate. Although this approach is straightforward, the impact of convection is often overlooked or its effect disregarded when stir speeds or flow rates are not provided with electrochemical or amperometric sensing results.

Enhancement of the analyte introduction rate can also be achieved for diffusive or convective environments by increasing the exposed catalytic surface area. High surface area microstructures promote intimate contact between the analyte and the catalytic surfaces while minimizing the structure's spatial footprint. Microstructures such as three-dimensional graphene [13-15], magnesium oxide [16-18], and zeolites [19-21], all possess considerably large surface area to fluid volume ratios and can be appropriately functionalized for specific chemical reactions. In particular, high-aspect-ratio microstructures (pillars, channels, etc.) allow for large exposure of surface area 
to chemical volume and facilitate enhanced mass transport, much in the same way fin arrays are used to enhance heat transfer $[22,23]$. The utility of enhanced surface area structures in the literature have been shown to outperform similar planar geometries [24, 25].

While external flow past microstructures can provide enhanced mass transport, internal flow through high-aspect-ratio microstructures allows for a third transport enhancement method: boundary layer confinement. For flow in a confined geometry such as a channel, concentration boundary layer growth is limited once the boundary layers have merged, resulting in a maximum transport distance of half the channel diameter. These short transport lengths result in high mass transport coefficients, especially as the channel diameter is reduced. The concept of flow-through electrodes originates in the 1970s [26-28], with application to hydrogen peroxide sensing beginning in the 1990s [29, 30]. However, with recent developments in microfabrication and materials science, the ability to sense target analyte has greatly increased, yet many sensors have not taken advantage of flowing analyte through the sensor. For example, carbon nanotubes (CNTs) have been widely used in electrochemical sensing because of their unique structural, mechanical, and electronic properties [31]. CNTs on supporting membranes have been used as flow-through electrodes for electrochemical filtering [32], but only recently have membrane-supported CNT flow-through electrodes been used for electrochemical sensing [33]. The present work describes a free-standing CNT sensor with an array of micron-scale channels (2,000-32,000 channels per $\left.\mathrm{mm}^{2}\right)$, a structure we previously used for the decomposition of hydrogen peroxide $\left(\mathrm{H}_{2} \mathrm{O}_{2}\right)$ at high concentrations for underwater vehicle propulsion [34]. Such a multi-channel CNT structure presents a departure from previous work as it is the first time CNTs have been arrayed in controlled patterns with flow through micron channels developed within the CNT membrane itself. Thus, this works presents the first steps in developing a more controlled CNT membrane for flow-through electrochemical microfluidic sensing devices (EMSDs) applications where the CNT membrane itself acts both as the highly catalytic working electrode and as the structure used to induce tunable microfluidic transport. These multi-channel CNT structures could also be fitted and placed within various sized flow channels including conventional microfluidic channels.

The importance of microfluidic transport in the context of electrochemical sensing/biosensing has shown to be tremendous promising in achieving efficient catalysis and low detection limits [35]. Such microfluidic sensing devices produce fast analysis times with extremely low sample and reagent volumes which is well-suited for point-of-service detection that circumvents the costs 
associated with conventional laboratory analysis (e.g., shipping/handling costs, highly trained technicians to operate polymerase chain reaction (PCR) or perform enzyme-linked immunosorbent assays (ELISAs) ) [36, 37]. Furthermore, EMSDs overcome challenges with optical-based sensing modalities where solution turbidity, optical path length, and power requirements can significantly hinder sensing results. However, there still exists a need to increase the sensitivity of EMSDs, and microfluidic sensors in general, as high sensitivity is required to detect target analytes in low concentrations or low volumes [38].

Herein, we increase the efficiency of electrochemical sensors that utilize convective flow environments by developing a high-aspect ratio, free-standing membrane ( $250 \mu \mathrm{m}$ height $)$ of vertically aligned carbon nanotubes (CNTs) that form an array of aligned, parallel microchannels (of $4 \mu \mathrm{m}$ diameter with 32,479 channels per $\mathrm{mm}^{2}$ or of $16 \mu \mathrm{m}$ diameter with 2,030 channels per $\mathrm{mm}^{2}$ ). The overall sensor dimensions can be scaled up to accommodate macroscale flow cells or any specific EMSD dimension where the fluid flow can be forced through a series of sensing microchannels. Subsequently, this CNT architecture capitalizes on all three mass transport enhancement methods to improve electrochemical sensing: high flow rate, large electroactive surface area, and concentration boundary layer confinement. The sensor architecture is realized through CNT-templated microfabrication, where CNTs are used as a scaffold to create a microporous membrane and achieve high-surface area to fluid volume structures that are electrically conductive. The structure is coated with urchin-like platinum nanowires ( $\mathrm{PN})$, developed through an electroless Pt deposition technique we have previously developed for use on CNTs, cellulose, and silicon oxide $[34,39,40]$, to increase the CNT structures electrocatalytic capability during subsequent non-enzymatic, amperometric sensing of $\mathrm{H}_{2} \mathrm{O}_{2}$. Experiments reveal that stir speed and sensor orientation can greatly affect the current response of the PN-coated CNT (PN-CNT) sensors. Through-flow sensing (i.e., flow through the sensor architecture as would be experienced if the PN-CNT membranes spanned across the flow path of an EMSD) is shown to produce drastically higher signals at lower local fluid velocities than achieved with the traditional method of stirring. Further, we demonstrate near complete detection $(>90 \%)$ of $\mathrm{H}_{2} \mathrm{O}_{2}$ at concentrations down to $50 \mathrm{nM}$ through exploitation of the sensor geometry and convective enhancement. Therefore, the CNT sensing platform utilized here offers an efficient method for chemical sensing/biosensing and shows promise for incorporation into the flow field of EMSD and larger macroscale flow cells as portrayed in this work. 


\section{Materials and Methods}

\subsection{CNT Sensing Platform}

Fabrication of the CNT sensing platform followed the methods outlined by Marr et al. [34]. An aluminum oxide $\left(\mathrm{Al}_{2} \mathrm{O}_{3}\right)$ film approximately $50 \mathrm{~nm}$ thick was deposited on a silicon $(\mathrm{Si})$ wafer using a Denton e-beam evaporator. A $7 \mathrm{~nm}$ layer of iron ( $\mathrm{Fe})$ was thermally evaporated onto patterned photoresist to achieve two different CNT sensor pore geometries (4 $\mu \mathrm{m}$ and $16 \mu \mathrm{m}$ diameter microchannels). The wafer was agitated in N-Methyl-2-pyrrolidone (NMP) for at least 10 minutes to remove the patterned photoresist in a lift-off process, resulting in a hexagonally packed arrangement of $\mathrm{Fe}$ free regions. The layers of construction for the CNT architecture are illustrated in Fig. 1A.

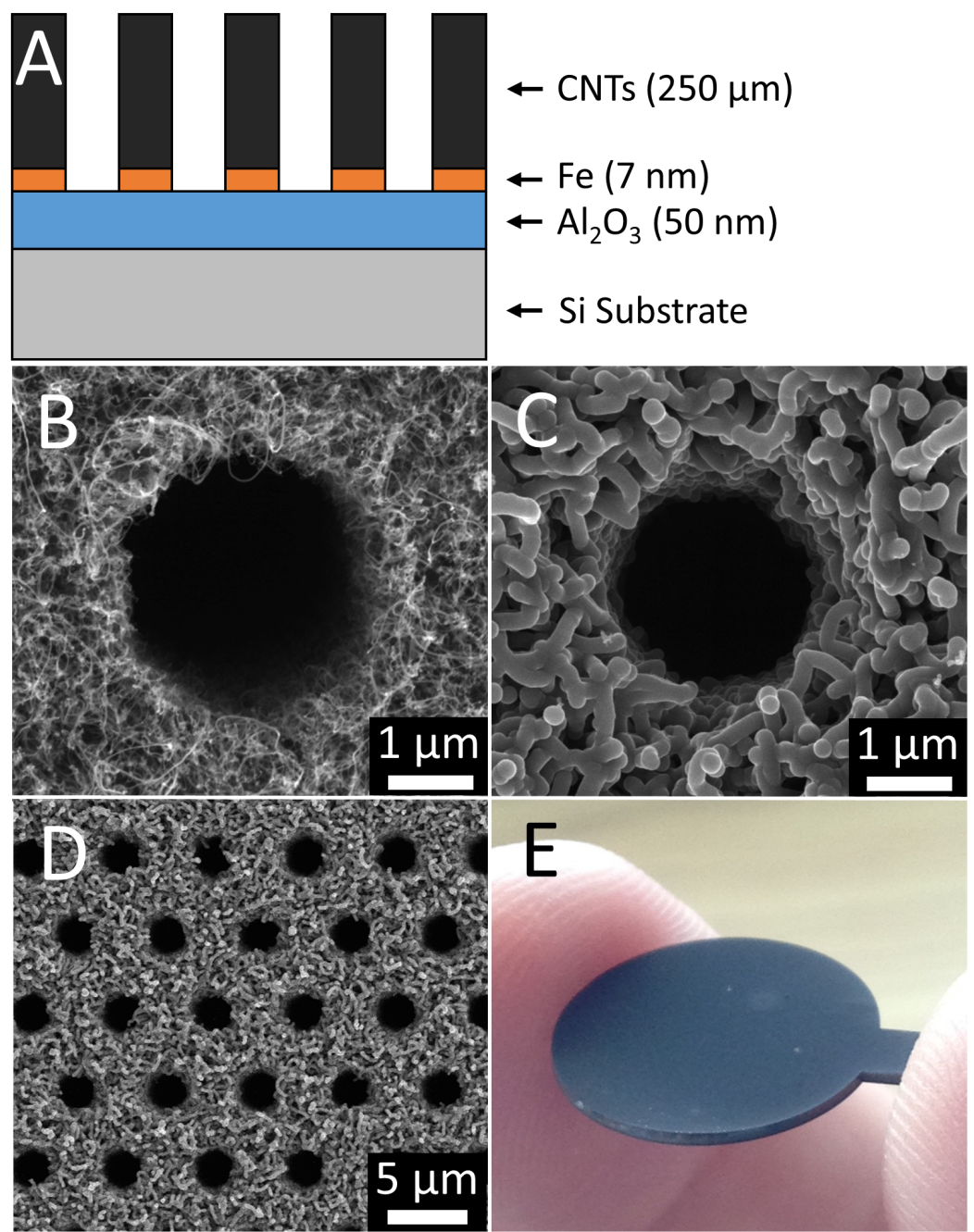

Fig. 1. (A) Schematic of layers used to manufacture the CNT sensor architecture: $\mathrm{Si}, \mathrm{Al}_{2} \mathrm{O}_{3}, \mathrm{Fe}$, and CNTs. Scanning electron microscope (SEM) images of CNTs that form microchannels with a nominal $4 \mu \mathrm{m}$ diameter (B) immediately 
after growth, (C) coated with amorphous carbon after infiltration, and (D) an array of porous-walled-microchannels aligned with the direction of the bulk CNT growth. (E) Sample CNT sensor after self-release from the Si substrate.

Diced Fe-patterned wafers were placed in a Lindberg/Blue M Tube Furnace for CNT growth in flowing hydrogen $(230 \mathrm{sccm})$ and ethylene $(250 \mathrm{sccm})$ at $750{ }^{\circ} \mathrm{C}$ for 6 minutes. After 6 minutes of growth, the multi-walled CNTs achieved a height of about $250 \mu \mathrm{m}$ with diameters on the order of $20 \mathrm{~nm}$ (see Fig. 1B), but require somewhat delicate handling. To create a stronger, agglomerated structure, the CNTs were coated (infiltrated) with amorphous carbon in the furnace by flowing hydrogen $(158 \mathrm{sccm})$ and ethylene $(250 \mathrm{sccm})$ at $900{ }^{\circ} \mathrm{C}$ for 10 minutes (see Fig. 1C). This infiltration/coating process with amorphous carbon results in the attachment of neighboring CNTs and enables a mechanically robust yet porous array of microchannels (see Fig. 1D). The hydrogen gas during carbon infiltration allows the CNT microstructure to self-release from the Si substrate, creating a stand-alone microstructure comprised of carbon-coated, CNT walls (see Fig. 1E).

Although the CNT membranes self-released from the wafers, the side closest to the Si substrate was covered by a thin carbon layer during infiltration. To remove this layer, an oxygen $\left(\mathrm{O}_{2}\right)$ plasma etch was performed for 5 minutes in an Anelva Reactive Ion Etcher DEM-451 (300 W, $3.1 \mathrm{sccm} \mathrm{O}_{2}$ ). An additional 2 minute etch was performed on the top face of the released structure to render the carbon surfaces hydrophilic.

\subsection{Platinum Deposition}

Platinum nanowires (PNs) were deposited onto the CNT sensors in a static, electroless environment using a chemical reduction of chloroplatinic acid hexahydrate $(37.5 \% \mathrm{Pt}$, SigmaAldrich 206083) similar to our previous protocols [34, 39, 40]. The concentration used in each deposition was dependent on the mass of the CNT sensor, with a target of $30 \% \mathrm{Pt}$ to carbon weight in solution $(2.9 \pm 0.4 \mathrm{mM}$ chloroplatinic acid). Each CNT sensor was held vertically in a Teflon stand for 24 hours in a solution containing chloroplatinic acid, $18 \mathrm{~mL}$ of ultrapure water and $2 \mathrm{~mL}$ of formic acid (88\% $\mathrm{HCOOH}$, Macron 2592-05). After the deposition, the samples were soaked in deionized water for 5 minutes and then placed in a dehydration oven for 10 minutes. The resulting Pt coverage on the CNTs is shown in Fig. 2. 


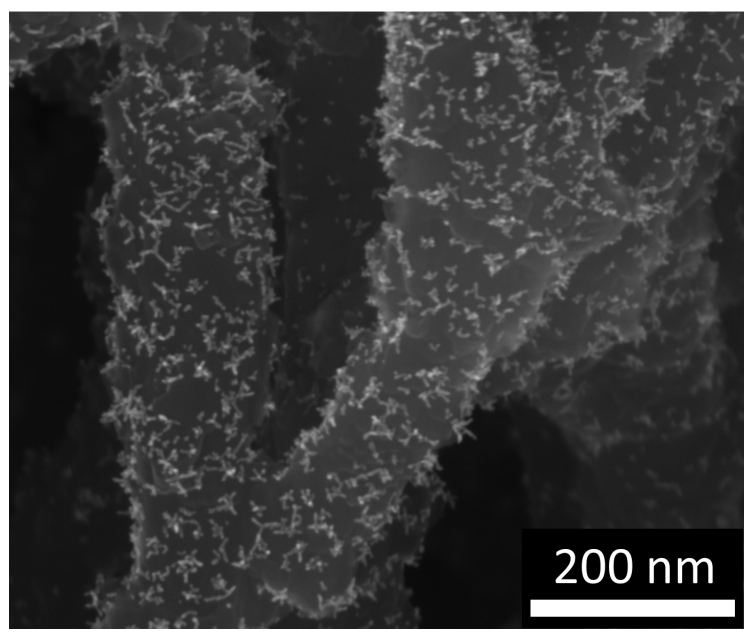

Fig. 2. SEM image of Pt coverage on CNTs as found near the axial center of the microchannel.

\subsection{Amperometric Measurements}

All experiments were performed in a three electrode electrochemical cell connected to a $\mathrm{CHI}$ 660 Potentiostat/Galvanostat. A Ag/ $\mathrm{AgCl}$ reference electrode in saturated $\mathrm{KCl}$, a Pt wire counter electrode, and the PN-CNT sensor as the working electrode were used. Amperometric sensing experiments were performed at a potential of $650 \mathrm{mV}$ relative to $\mathrm{Ag} / \mathrm{AgCl}$. Before experiments were performed, this potential was applied to the buffer solution until a steady baseline current was achieved from the buffer solution alone.

Non-enzymatic amperometric sensing experiments were performed with $\mathrm{H}_{2} \mathrm{O}_{2}$ to illustrate the influence of convection and mass transfer on chemical sensing. Electrical current was produced from the oxidation reaction of $\mathrm{H}_{2} \mathrm{O}_{2}$, as shown in Eq. 1 .

$$
\mathrm{H}_{2} \mathrm{O}_{2} \rightarrow \mathrm{O}_{2}+2 \mathrm{H}^{+}+2 e^{-}
$$

Two electrons correspond to one molecule of oxidized $\mathrm{H}_{2} \mathrm{O}_{2}$, allowing the direct correlation between current and oxidation rate using the rate form of Faraday's law shown in Eq. 2,

$$
N=\frac{I}{n F}
$$

where $\mathrm{N}$ is the molar oxidation rate of $\mathrm{H}_{2} \mathrm{O}_{2}\left(\mathrm{~mol} \mathrm{~s}^{-1}\right)$, I is the current $(\mathrm{A}), \mathrm{n}$ is the moles of electrons per mole of $\mathrm{H}_{2} \mathrm{O}_{2}$, and $\mathrm{F}$ is Faraday's constant, $96,485 \mathrm{C}\left(\mathrm{mol} \mathrm{e}^{-}\right)^{-1}$.

\subsection{Stirred Environment}

Stirred experiments were performed in a $50 \mathrm{~mL}$ glass beaker containing $30 \mathrm{~mL}$ of phosphate buffer saline (1X PBS, 7.4 pH, Fisher Scientific), as shown in Fig. 3A and B. The PN-CNT sensor was positioned vertically, close to the water level, such that the circular portion of the sensor was completely submerged, but the connecting tab (attached to Nichrome wire with Duralco 120 silver 
epoxy) was not submerged. Two orientations were examined: the PN-CNT sensor positioned parallel to the flow (Fig. 3A) and perpendicular to the flow (Fig. 3B). An $8 \mathrm{~mm}$ diameter stir bar $(2.5 \mathrm{~cm}$ in length) at the bottom of the beaker provided the fluid motion using a Thermo Scientific Super-Nuova stir plate to control the stir speeds. The concentration of $\mathrm{H}_{2} \mathrm{O}_{2}$ did not change significantly during each test, except as noted in section 4.2.
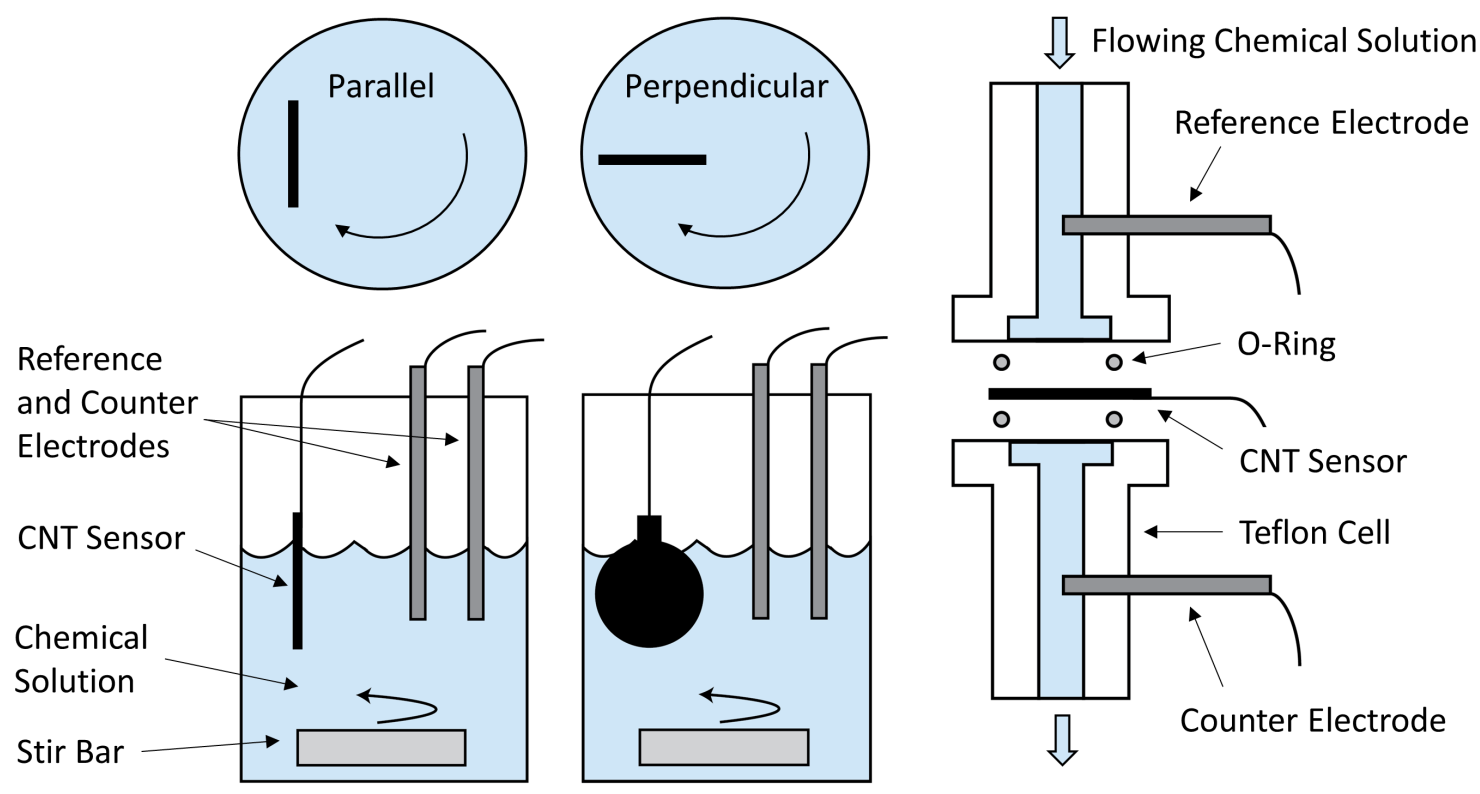

A

B

Fig. 3. Schematics of different convective environments tested using three electrode cells. Stirred conditions with the PN-CNT sensor oriented (A) parallel to flow and (B) perpendicular to flow. (C) Exploded view of through-flow conditions, where the chemical solution is forced through the PN-CNT microchannels.

\subsection{Through-flow Environment}

In through-flow experiments, $50 \mathrm{~mL}$ of PBS (same as in stirred experiments) was forced through the PN-CNT microchannels. The PN-CNT sensor was clamped together between two Orings in a machined Teflon electrochemical flow cell, shown in the exploded view in Fig. 3C. This configuration allowed forced mechanical contact between the sensor and a Nichrome wire (avoiding the need for silver epoxy used in stirred experiments). The flow cell was oriented vertically, with the reference electrode upstream and the counter electrode downstream of the PNCNT sensor. This configuration provided the greatest response to hydrogen peroxide, while still providing low background noise. A $60 \mathrm{~mL}$ syringe pulled the solution through the cell from a 
reservoir on the opposite side using a Harvard Apparatus PHD Ultra syringe pump to control the flow rate.

\section{Results}

\subsection{Characterization}

The PN-CNT sensors were $260 \pm 48 \mu \mathrm{m}$ in thickness, yielding aspect ratios (channel length/diameter) of about 16 and 65 for the 16 and $4 \mu \mathrm{m}$ diameter channels, respectively. The sensors had a frontal projected area of $1.56 \mathrm{~cm}^{2}(1.41 \mathrm{~cm}$ diameter $)$, with both geometries having the same void fraction of 0.413 . The surface area for a solid disk of this diameter and thickness would be $3.25 \mathrm{~cm}^{2}$. With $4 \mu \mathrm{m}$ channels passing through the disk, the nominal microchannel surface area would increase to $169 \mathrm{~cm}^{2}$. Since the microstructure is also porous, the actual surface area is significantly higher. A Brunauer-Emmett-Teller (BET) nitrogen absorption test yielded $19.86 \mathrm{~m}^{2} \mathrm{~g}^{-1}$ for the CNT sensors. Thus, for a nominal sample mass of $24.5 \pm 3.6 \mathrm{mg}$, the surface area would be $4,621 \pm 679 \mathrm{~cm}^{2}$, or a 1,400 times increase over the nominal solid disk.

The CNT membranes had PNs deposited on the surfaces, resulting in a $13.1 \pm 3.9 \mathrm{Pt}$ to carbon weight percent. PNs coverage was highest on the outer surfaces and became more sparse toward the axial center of the channels (see also [34]).

\subsection{Stirred Results}

Fig. 4A shows the current response in time from a typical set of experiments, where three repeat stirred experiments are shown for the $16 \mu \mathrm{m}$ channel CNT geometry in the parallel orientation. The baseline currents for different stir speeds (0 (static), 50, 100, 200, $300 \mathrm{rpm}$ ) were monitored in one minute intervals. At 300 seconds, $3 \% \mathrm{H}_{2} \mathrm{O}_{2}$ by weight $\left(0.89 \mathrm{M} \mathrm{H}_{2} \mathrm{O}_{2}\right)$ was added to the cell to obtain a target concentration of $100 \mu \mathrm{M} \mathrm{H}_{2} \mathrm{O}_{2}$. This injection of $\mathrm{H}_{2} \mathrm{O}_{2}$ caused an immediate spike in measured current, which was monitored for three minutes (see central plateau region of Fig. 4A and Fig. 4B). Then, the same stir speeds were stepped through in reverse order over one minute intervals until the cell returned to a static condition. 
A

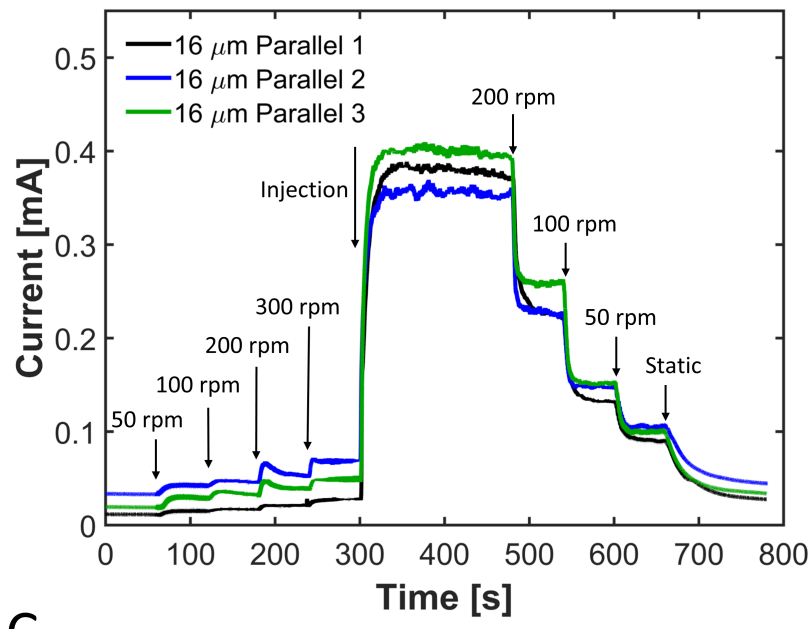

C

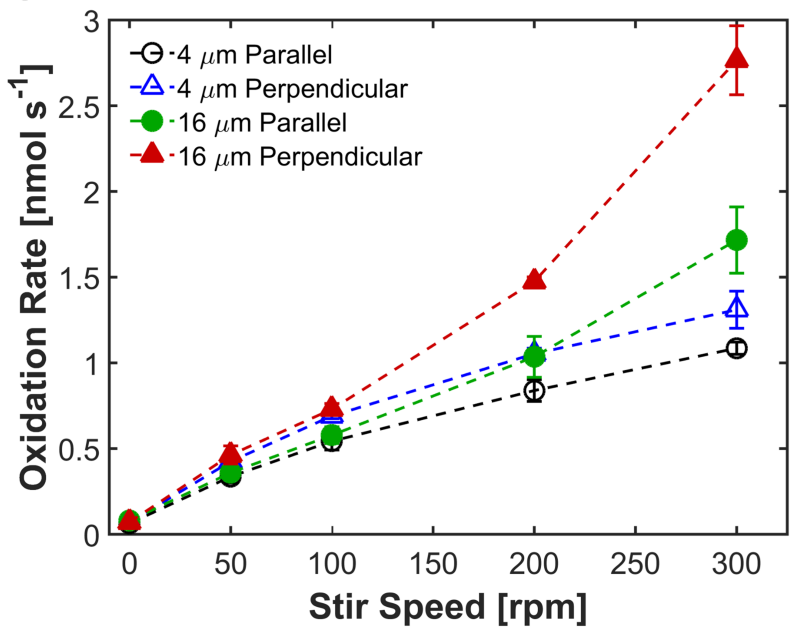

B

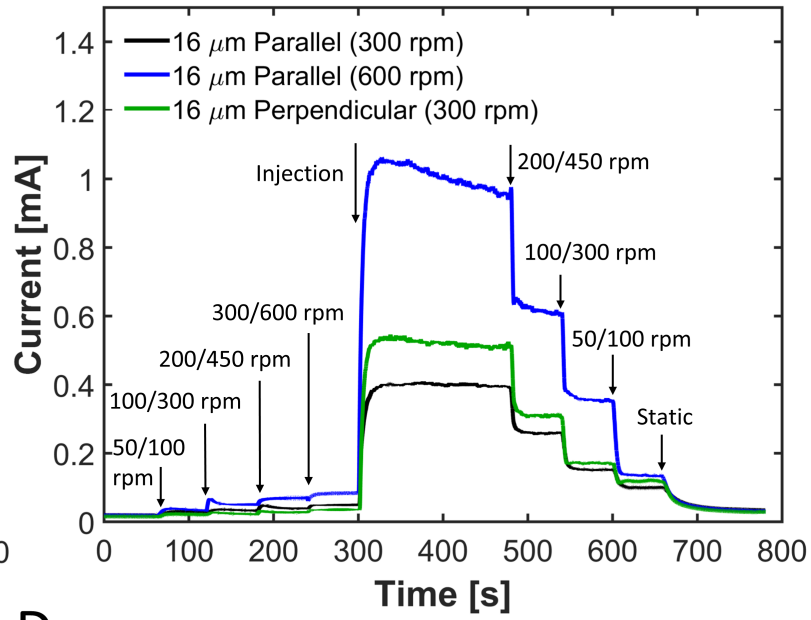

D

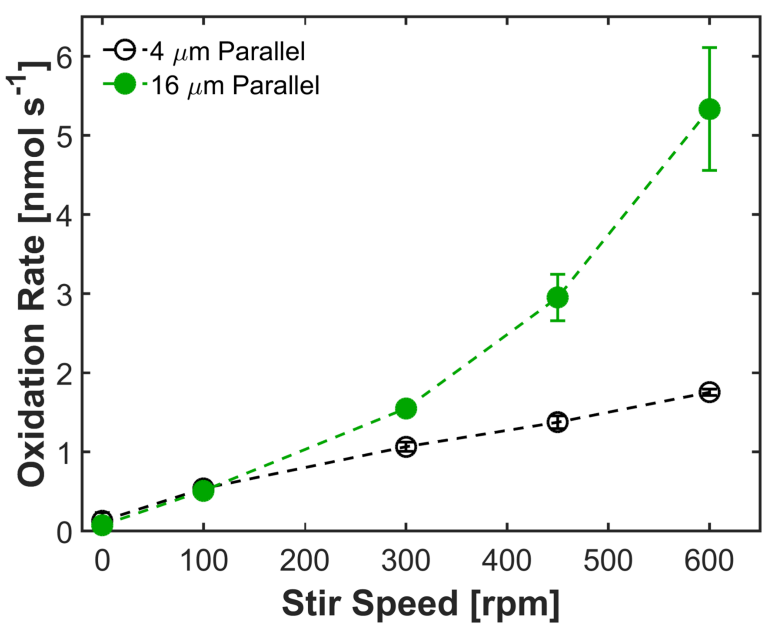

Fig. 4. (A) Measured current for three separate $16 \mu \mathrm{m}$ diameter PN-CNT sensors in response to an injection of 100 $\mu \mathrm{M} \mathrm{H}_{2} \mathrm{O}_{2}$ for different stir speeds. The sensor is oriented parallel to the flow, with the injection of $\mathrm{H}_{2} \mathrm{O}_{2}$ at 300 seconds is monitored for 3 minutes (central plateau region) while stirring at $300 \mathrm{rpm}$, after which the stir speed is incrementally lowered, as indicated. (B) Comparison of current response for sample PN-CNT sensors in the parallel orientation (up to $300 \mathrm{rpm}$ and $600 \mathrm{rpm}$ ) and in the perpendicular orientation (up to $300 \mathrm{rpm}$ ). The first/second indicated stir speeds correspond to testing up to a max stir speed of 300/600 rpm, respectively. (C) Oxidation rates in response to $100 \mu \mathrm{M}$ $\mathrm{H}_{2} \mathrm{O}_{2}$ at various stir speeds for parallel and perpendicular sensor orientations with 4 and $16 \mu \mathrm{m}$ diameter channels relative to the flow. (D) Oxidation rates for the parallel orientation up to $600 \mathrm{rpm}$ for both 4 and $16 \mu \mathrm{m}$ diameter geometries. In all cases, error bars represent the standard deviation of three measurements.

The results of the parallel orientation from Fig. 4A were compared to two other stirred environments using the same PN-CNT sensors (16 $\mu$ m diameter channels) in $100 \mu \mathrm{M} \mathrm{H}_{2} \mathrm{O}_{2}$ (see Fig. 4B). In the first comparison, the PN-CNT sensor was oriented perpendicular to the flow and tested at the same stir speeds ( 0 (static), 50, 100, 200, $300 \mathrm{rpm}$ ). The second comparison considered stir speeds up to $600 \mathrm{rpm}$ (0 (static), 100, 300, 450, and $600 \mathrm{rpm}$ ) in the parallel orientation. Both of these comparison conditions gave higher currents than the parallel orientation up to $300 \mathrm{rpm}$; however, at $600 \mathrm{rpm}$ the measured current appears to decrease by $13 \%$ due to a change in the 
solution concentration, as discussed further in section 4.2. Tests were not performed in the perpendicular orientation at $600 \mathrm{rpm}$ due to the strain it placed on the PN-CNT sensor.

It can be seen from Fig. $4 \mathrm{~A}$ and $\mathrm{B}$ that the measured current was strongly dependent on stir speed, with the highest current achieved at the highest tested stir speed. The current changed suddenly with each reduction in stir speed, showing a strong correlation between the convective environment and the measured current.

For each stir speed, orientation, and channel diameter, the change in current before and after the $\mathrm{H}_{2} \mathrm{O}_{2}$ injection was used to calculate the oxidation rate of $\mathrm{H}_{2} \mathrm{O}_{2}$ (see Eq. 2). A comparison between the oxidation rates for the parallel and perpendicular orientations up to $300 \mathrm{rpm}$ for the 4 and $16 \mu \mathrm{m}$ diameter geometries is shown in Fig. 4C. In all cases, three separate CNT sensors were tested for each geometry to obtain the standard deviation of the response. At $100 \mathrm{rpm}$ and lower, the differences in oxidation rates between the different orientations and geometries are minimal. However, as stir speed increases to $300 \mathrm{rpm}$, the $16 \mu \mathrm{m}$ sensors have higher oxidation rates, especially in the perpendicular orientation. For both channel diameter sizes, the perpendicular orientation gave higher oxidation rates than the parallel orientation. This indicates that stir speed, orientation and pore size (channel diameter) all influence the current response of a sensor.

Fig. 4D shows how oxidation rate increases with stir speed (up to $600 \mathrm{rpm}$ ) in the parallel orientation for both channel diameters. The oxidation rates for the $4 \mu \mathrm{m}$ diameter geometry appear to increase nearly linearly with stir speed after $100 \mathrm{rpm}$. However, a non-linear increase in oxidation rate with stir speed for the $16 \mu \mathrm{m}$ diameter geometry is observed. At $600 \mathrm{rpm}$, the oxidation rate of the $16 \mu \mathrm{m}$ sensor was about 3 times that of the $4 \mu \mathrm{m}$ sensor. The oxidation rate of the $16 \mu \mathrm{m}$ sensor also increased nearly 3 times when stir speed was doubled from 200 to 300 rpm.

\subsection{Through-flow Results}

To maximize the surface area of the PN-CNT sensor and to utilize boundary layer confinement, all the chemical solution was forced through the microchannels in a through-flow, convective environment (see Fig. 3C). The current densities for the $16 \mu \mathrm{m}$ geometry in response to $100 \mu \mathrm{M} \mathrm{H}_{2} \mathrm{O}_{2}$ at different flow rates $\left(10,25,50,75\right.$, and $\left.100 \mu \mathrm{L} \mathrm{s}^{-1}\right)$ are shown in Fig. 5A.

Current densities (which are normalized by area) are used in Fig. 5A to compare stirred and through-flow results because part of the frontal sensor area is outside of the O-ring used to seal the flow path in the through-flow arrangement. The stirred current is normalized by the frontal 
projected surface area $\left(1.56 \mathrm{~cm}^{2}\right)$ and the through-flow current is normalized by the area defined by the inner diameter of the O-rings $\left(0.713 \mathrm{~cm}^{2}\right)$.

The currents measured in through-flow arrangement were significantly higher than currents obtained in the stirred experiments because the microchannels kept the $\mathrm{H}_{2} \mathrm{O}_{2}$ close to the surface (where the reaction takes place), limiting the concentration boundary layer. The volumetric flow rate was a dominant controlling feature of the measured current, as there are sharp drops in current when the flow rate was lowered. The oscillations in the current observed after the injection of $\mathrm{H}_{2} \mathrm{O}_{2}$ (Fig. 5A, red curve after 300 seconds) correspond to the frequency of stepping in the syringe pump. This sensitivity to stepping in the syringe pump motor further indicates the dependence of the measured current on the convective environment, as slight changes in the flow rate caused by the syringe pump resulted in signal oscillations.
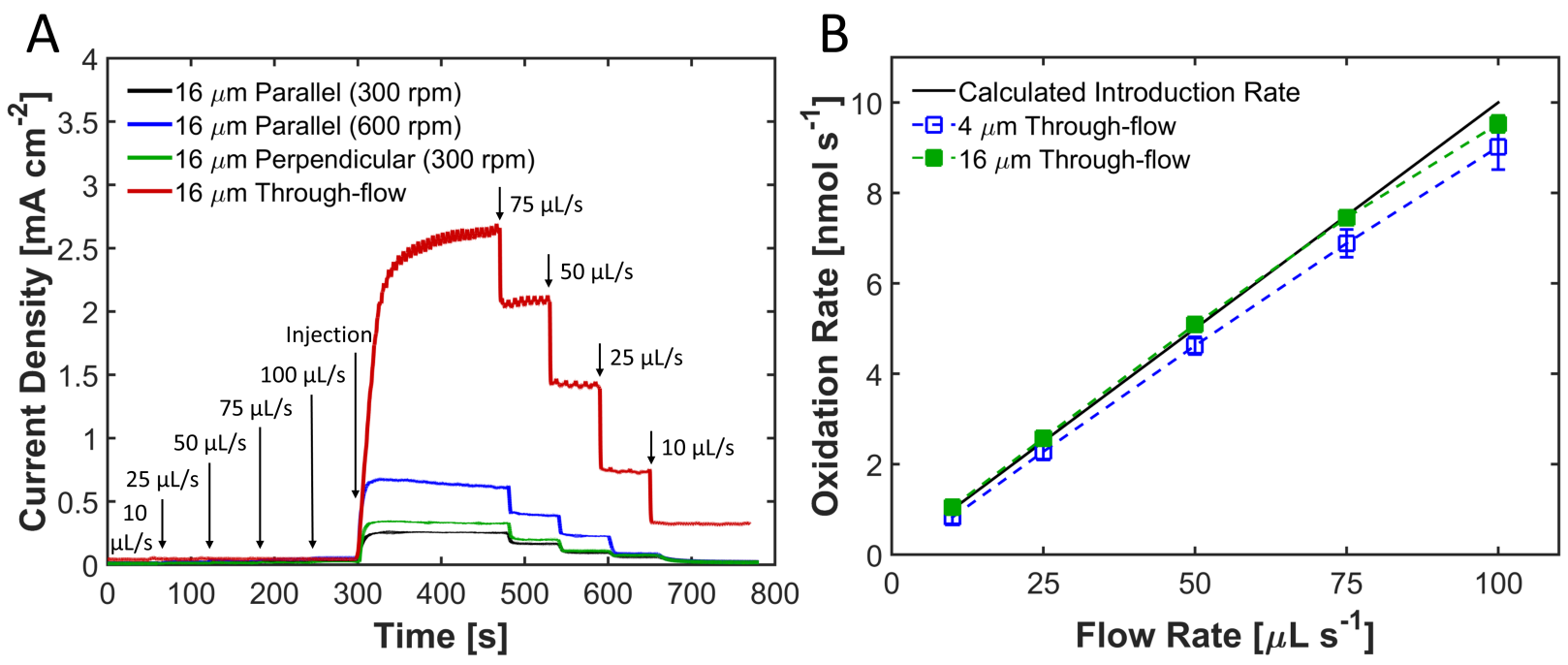

Fig. 5. (A) Through-flow current densities for the $16 \mu \mathrm{m}$ diameter channels in response to $100 \mu \mathrm{M} \mathrm{H}_{2} \mathrm{O}_{2}$ (injected at 300 seconds and measured for 180 seconds) at different flow rates $\left(10-100 \mu \mathrm{L} \mathrm{s}^{-1}\right)$ as compared to the current densities of the various stirred conditions for the same concentration of $\mathrm{H}_{2} \mathrm{O}_{2}$ (previously illustrated in Fig. 4B). (B) Throughflow oxidation rates in response to $100 \mu \mathrm{M} \mathrm{H}_{2} \mathrm{O}_{2}$ at different flow rates for both 4 and $16 \mu \mathrm{m}$ diameter channels are compared to the calculated introduction rates of $\mathrm{H}_{2} \mathrm{O}_{2}$. Error bars represent the standard deviation of three measurements.

The measured oxidation rates for the through-flow experiments are shown in Fig. 5B, where three PN-CNT sensors were again used for each geometry to obtain the standard deviation of the response. These oxidation rates are compared to the calculated introduction rates of $\mathrm{H}_{2} \mathrm{O}_{2}$ into the flow cell, which were determined from the known concentration of $\mathrm{H}_{2} \mathrm{O}_{2}$ and the volumetric flow rates. The introduction rate is the theoretical maximum oxidation rate at any given flow rate. The $16 \mu \mathrm{m}$ channel geometry obtained oxidation rates that were nearly identical to the introduction 
rates (with a slight drop to $95 \%$ at $100 \mu \mathrm{L} \mathrm{s}^{-1}$ ). This signifies that nearly all the $\mathrm{H}_{2} \mathrm{O}_{2}$ was oxidized as it passed through the PN-CNT sensor. The $4 \mu \mathrm{m}$ diameter channels had slightly lower oxidation rates at about $90 \%$ of the introduction rate. Oxidation rates for both geometries appeared to increase linearly with flow rate.

A

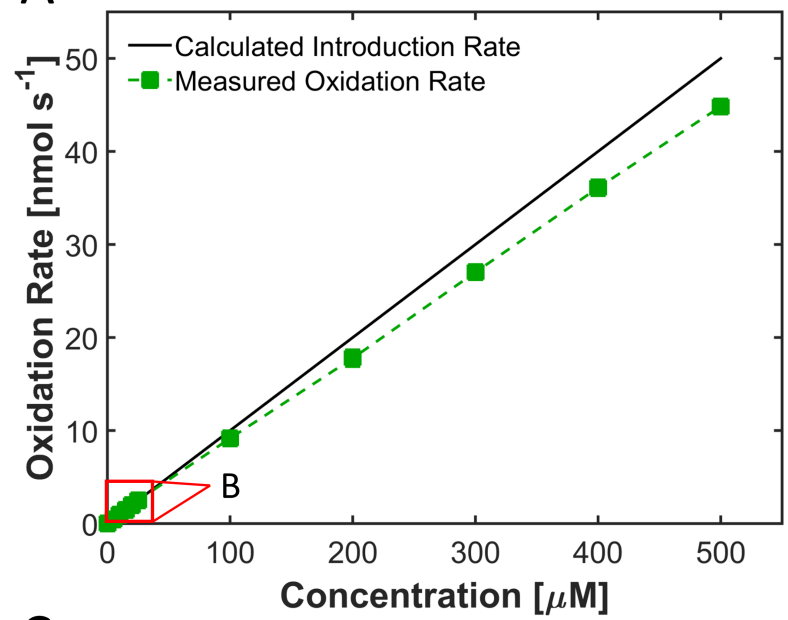

C

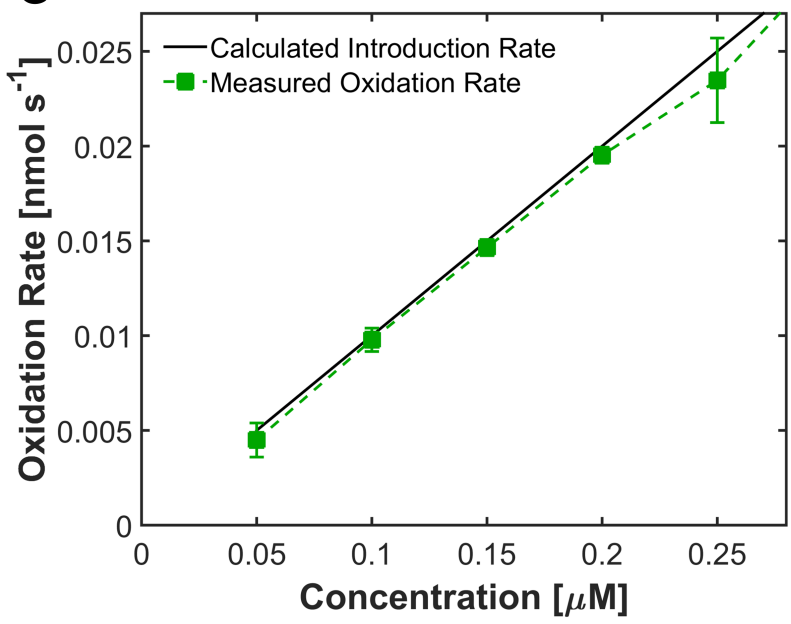

B

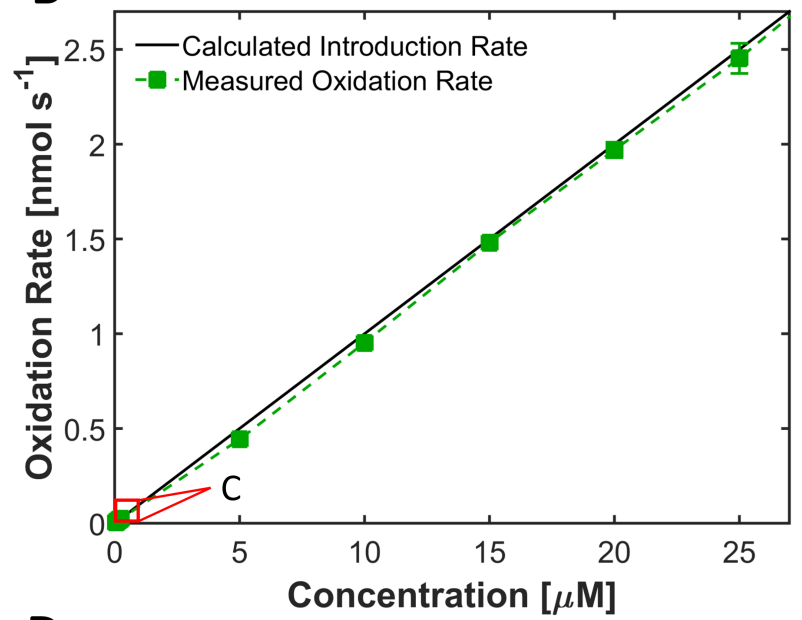

D

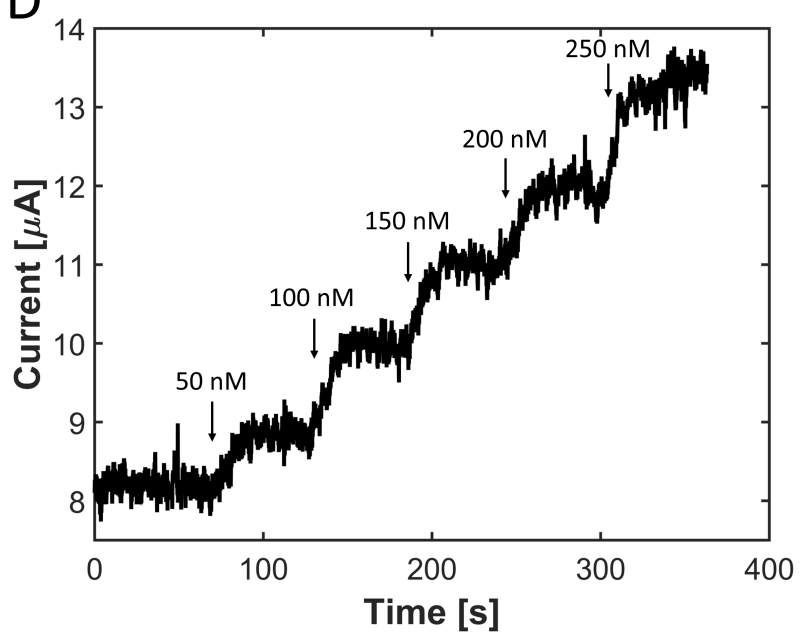

Fig. 6. (A) Linear range of $16 \mu \mathrm{m}$ diameter PN-CNT sensor at a flow rate of $100 \mu \mathrm{L} \mathrm{s} \mathrm{s}^{-1}$. (B) Close up linear range of (A) up to $25 \mu \mathrm{M}$. (C) Close up linear range of (B) up to $0.25 \mu \mathrm{M}$. This linear range is approaching the limit of detection of $0.03 \mu \mathrm{M}$. (D) The current measured in time for additions of $50 \mathrm{nM} \mathrm{H}_{2} \mathrm{O}_{2}$, which were used to determine the oxidation rates obtained in $(\mathrm{C})$. In all cases, error bars represent the standard deviation of three measurements.

\subsubsection{Through-flow Sensitivity, Limit of Detection and Linear Range}

The $16 \mu \mathrm{m}$ diameter PN-CNT sensor at a flow rate of $100 \mu \mathrm{L} \mathrm{s}^{-1}$ provided the highest oxidation rate when tested at $100 \mu \mathrm{M} \mathrm{H}_{2} \mathrm{O}_{2}$. Therefore, this geometry and convective environment were chosen to determine the sensitivity, limit of detection (LOD) and linear range for the sensor 
approach. Fig. 6A-C shows the complete linear range of the PN-CNT sensor, in the range of 50 $\mathrm{nM}$ to $500 \mu \mathrm{M}$, with the oxidation rates remaining linear over about $90 \%$ of the introduction rates.

The linear range can be seen at lower concentrations in Fig. 6B and at very low concentrations in Fig. 6C. The measured oxidation rates are very close to the introduction rates at these low concentrations, which is particularly useful in the detection of very low concentrations where it is desired to maximize the signal from the available analyte. Fig. 6D shows the current measured in time for the oxidation rates shown in Fig. 6C, at increments of $50 \mathrm{nM}$. The limit of detection (LOD) at $100 \mu \mathrm{L} \mathrm{s}^{-1}$ was $0.03 \mu \mathrm{M}$ (using a signal to noise ratio of $\mathrm{S} / \mathrm{N}=3$ ). Thus, Fig. $6 \mathrm{C}$ shows that the PN-CNT sensor is approaching the LOD while still remaining very linear. The linear range is then $0.03-500 \mu \mathrm{M}$.

The sensitivity (current/molarity) of the PN-CNT sensor was determined to be $17,300 \mu \mathrm{A}$ $\mathrm{mM}^{-1}$. Normalizing by the $2 \mathrm{D}$ surface area similar to other researchers (frontal projected area $=$ $0.713 \mathrm{~cm}^{2}$ ) gives a sensitivity of $24,300 \mu \mathrm{A} \mathrm{mM} \mathrm{mm}^{-1} \mathrm{~cm}^{-2}$ This is an extremely high sensitivity as noted in Table 1. If one were to include the nominal microchannel surface area in the normalization

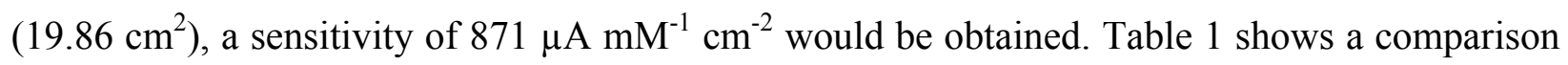
of sensitivity with some recent Pt-based, non-enzymatic $\mathrm{H}_{2} \mathrm{O}_{2}$ sensors with our sensitivity ranking among some of the highest reported, regardless of the method for normalizing with area. Four electrodes (including the one in this work) are marked with an asterisk in the table to indicate that they were tested in channel flow. Generally speaking, the sensitivity of these electrodes in a flowing environment was significantly higher than other electrodes in the table, likely due to enhanced mass transfer through convective channel flow. The PN-CNT sensor also had a lower LOD than all but four of the sensors, but only two of those sensors remained linear near the limit of detection.

Table 1: Sensitivity, limit of detection (LOD), and linear sensing range comparison with recent Pt-based, nonenzymatic $\mathrm{H}_{2} \mathrm{O}_{2}$ sensors.

\begin{tabular}{llllll}
\hline Electrode & $\begin{array}{l}\text { Potential } \\
(\mathrm{V}(\mathrm{Ag} / \mathrm{AgCl}))\end{array}$ & $\begin{array}{l}\text { Sensitivity } \\
\left(\mu \mathrm{AmM}^{-1} \mathrm{~cm}^{-2}\right)\end{array}$ & $\begin{array}{l}\text { LOD } \\
(\mu \mathrm{M})\end{array}$ & $\begin{array}{l}\text { Linear Range } \\
(\mu \mathrm{M})\end{array}$ & Reference \\
\hline CV-activated Pt-black* & 0.3 & 4,080 & 0.01 & $0.01-300$ & {$[41]$} \\
Pt strips* & - & - & 0.41 & - & {$[42]$} \\
Pt/Te-microtubes* & $-0.15^{* *}$ & 2,000 & 0.001 & $0.5-30,000$ & {$[43]$} \\
SPGFE/MWCNTC/PtNP & -0.4 & - & 1.23 & $5-2,000$ & {$[44]$} \\
PtPd-MWCNTs & $0.65^{* *}$ & 393 & 8 & $12-14,000$ & {$[45]$} \\
PVA-MWCNTs-PtNPs & 0 & 122.63 & 0.7 & $2-3,800$ & {$[46]$} \\
CoNP-Pt/CNTs & $-0.15^{* *}$ & 744 & 0.1 & $0.2-1,250$ & {$[47]$} \\
MWCNTs/Pt nanohybrids & 0 & 205.8 & 0.3 & $10-2,000$ & {$[48]$}
\end{tabular}




\begin{tabular}{llllll} 
PtNPs/MWCNTs-SDS & $-0.05^{* *}$ & - & 0.0019 & $0.0058-1,100$ & {$[49]$} \\
Pt hierarchical nanoflower & 0.21 & 1,390 & 0.32 & $10-400$ & {$[50]$} \\
Pt/graphene-CNT paper & -0.05 & 1,410 & 0.01 & $0.1-25$ & {$[51]$} \\
Fe@Pt/C & $-0.35^{* *}$ & 218.97 & 0.75 & $2.5-41,600$ & {$[52]$} \\
aHPM & 0.8 & - & 1.69 & $0.87-167$ & {$[53]$} \\
PN-CNT microchannels* & 0.65 & $24,300^{\dagger} / 871^{\S}$ & 0.03 & $0.03-500$ & This work \\
\hline
\end{tabular}

*Convection enhanced via channel flow

** potential converted from saturated calomel electrode ( $\mathrm{SCE}$ ) to $\mathrm{Ag} / \mathrm{AgCl}$ reference electrode (about $0.05 \mathrm{~V}$ increase)

$\dagger$ based on frontal projected surface area

$\S$ based on nominal microchannel surface area

\section{Discussion}

\subsection{Influence of Convection}

The results for stirred and through-flow configurations have shown the significant impact of convection on sensing platforms. The signal strength obtained in traditional three-electrode cell configurations can be highly dependent on stir speed and orientation. Although others have shown that covering a sensor with a membrane may reduce the influence of stir speed [53], the influence of convection should generally not be ignored. As such, stir speed and orientation should be reported when amperometric results are presented.

It is likely that both the 4 and $16 \mu \mathrm{m}$ diameter sensors demonstrated higher oxidation rates in the perpendicular orientation because the flow acted as an impinging jet, increasing the mass transfer coefficient when compared to flow parallel to the sensor. The sensor with $16 \mu \mathrm{m}$ diameter channels offered oxidation rates that were significantly higher than the $4 \mu \mathrm{m}$ sensor in the perpendicular orientation, likely because the $\mathrm{H}_{2} \mathrm{O}_{2}$ solution more easily penetrated into the microchannels, taking advantage of additional surface area and increasing the oxidation rate. The $4 \mu \mathrm{m}$ channels may be too small to allow the solution to easily enter the channels when stirring, limiting the reaction only to the outer surfaces of the sensor. Further, it is likely that the smaller diameter sensors have a lower amount of Pt deposition inside the microchannel area, as the deposition method is diffusion dominated.

Similarly, the observed non-linear increase in oxidation rate with stir speed for the $16 \mu \mathrm{m}$ sensors in both the parallel and perpendicular orientations may be caused by an increase in the amount of solution that enters the channels. Thus, the oxidation rates of porous sensors with the larger microchannel diameters appear to be more sensitive to changes in stir speed and orientation.

It was also shown that flowing the chemical solution through the PN-CNT sensor greatly increased the oxidation rates when compared to stirred conditions. Not only were the oxidation 
rates much higher for through-flow conditions, these higher oxidation rates were achieved at significantly lower local velocities than the stirred environments. For the maximum flow rate of $100 \mu \mathrm{L} \mathrm{s}^{-1}$, the average velocity through the microchannels was only $0.34 \mathrm{~cm} \mathrm{~s}^{-1}$. For the maximum stir speed of $600 \mathrm{rpm}$ (assuming the velocity of the fluid past the sensor to be approximated by the local velocity of the stir bar) the velocity was $62.8 \mathrm{~cm} \mathrm{~s}^{-1}$. Thus, the relative fluid velocity at 100 $\mu \mathrm{L} \mathrm{s}^{-1}$ was only about $0.55 \%$ the velocity at $600 \mathrm{rpm}$, while still achieving nearly double the oxidation rate with less than half of the surface area. The drastic improvement in measurement signal for the through-flow configuration, relative to a stirred condition, is due to the intimate contact between analyte and sensing surface achieved through limiting the concentration boundary layer by forcing the liquid through the sensor architecture.

A lower fluid velocity in through-flow sensing may also provide less noise in the signal relative to stirred conditions. In stirred experiments, it was observed that the baseline current increased with increasing stir speeds, despite reducing the buffer solution for more than 30 minutes. In through-flow testing, there was a slight increase in baseline current from static to flowing buffer solution before $\mathrm{H}_{2} \mathrm{O}_{2}$ injection, possibly caused by a streaming current from flowing solution through the PN-CNT sensor. However, the baseline current remained nearly constant when increasing from 10 to $100 \mu \mathrm{L} \mathrm{s}^{-1}$ in through-flow (Fig. 5A), suggesting the effects of a streaming current were negligible. Regardless, the current response was determined by subtracting the baseline current for the buffer solution from the measured current after $\mathrm{H}_{2} \mathrm{O}_{2}$ injection at the same flowrate, thereby removing any effect of streaming current from the buffer solution. The increase in current from static to $600 \mathrm{rpm}$ before injecting $\mathrm{H}_{2} \mathrm{O}_{2}$ was about $6 \%$ of the measured step change at $600 \mathrm{rpm}$ for $100 \mu \mathrm{M} \mathrm{H}_{2} \mathrm{O}_{2}$, while the slight increase in current from 10 to $100 \mu \mathrm{L}$ $\mathrm{s}^{-1}$ before injecting $\mathrm{H}_{2} \mathrm{O}_{2}$ was only $0.2 \%$ of the measured step change at $100 \mu \mathrm{L} \mathrm{s}^{-1}$ for $100 \mu \mathrm{M}$ $\mathrm{H}_{2} \mathrm{O}_{2}$.

\subsection{Concentration Change in Time}

It should be noted that the concentration of $\mathrm{H}_{2} \mathrm{O}_{2}$ reduced in time over the duration of the stirred experiments. This was most noticeable with the $16 \mu \mathrm{m}$ diameter sensor at $600 \mathrm{rpm}$, as seen by the downward slope in the current after the injection of $\mathrm{H}_{2} \mathrm{O}_{2}$ (see Fig. 4B). Three minutes after the injection of $\mathrm{H}_{2} \mathrm{O}_{2}$, the measured current dropped approximately $13 \%$. In contrast, the measured current of the $4 \mu \mathrm{m}$ diameter sensors at $600 \mathrm{rpm}$ only dropped by about $4 \%$ after three minutes because the oxidation rate was only one third the oxidation rate of the $16 \mu \mathrm{m}$ diameter sensors. 
In a through-flow environment, the $\mathrm{H}_{2} \mathrm{O}_{2}$ concentration upstream of the PN-CNT sensor does not change in time because the oxidized solution moves through the sensor, such that the current does not decrease in time at a constant flow rate. This allows for very high oxidation rates without having to correct for concentrations changing in time.

\subsection{Limitations}

A major factor that limited the upper end of the sensing range was the formation of oxygen bubbles due to the high oxidation rates of $\mathrm{H}_{2} \mathrm{O}_{2}$ (see Eq. 2). Because the experiments were performed by withdrawing the syringe pump, the resulting bubbles in the liquid line had the potential to cause discontinuity in the measured signal. An alternative approach would be to perform the experiments with infusion pumping, such that the generated gases are swept toward a free surface and do not obstruct the signal at high $\mathrm{H}_{2} \mathrm{O}_{2}$ concentrations.

The detection limit of the PN-CNT sensor could potentially be improved by increasing the flow rate above $100 \mu \mathrm{L} \mathrm{s}^{-1}$ to obtain higher current responses for the same $\mathrm{H}_{2} \mathrm{O}_{2}$ concentration. It appeared that slight variations in the Pt coverage had little effect on the sensor signal; however, samples without Pt had a very low response with $<2 \%$ of the measured oxidation rate for PN-CNT sensors at $100 \mu \mathrm{L} \mathrm{s}^{-1}$ (see Figure SI 1 in the supplementary material).

\section{Conclusions}

This work highlights the utility of convection in detecting low analyte concentrations. The approaches to exploit the use of convection help to increase the sensitivity of electrochemical sensors incorporated into microfluidic devices. In particular, we have shown how high-aspect-ratio PN-CNT sensors provide a unique sensing platform that enhances mass transfer by enabling high flow rates and surface area, and confining concentration boundary layers. PN-CNT sensor performance was measured by the non-enzymatic amperometric sensing of $\mathrm{H}_{2} \mathrm{O}_{2}$, where it was shown that convection had a significant influence on the measured current. Stir speed and sensor orientation were two factors that affected sensors in stirred environments, especially for those with microchannel diameters of $16 \mu \mathrm{m}$. Through-flow sensing oxidized over $90 \%$ of the $\mathrm{H}_{2} \mathrm{O}_{2}$ as it passed through the PN-CNT sensor, producing drastically higher currents at lower velocities than stirring. The high current response obtained by flow through the PN-CNT microchannels resulted in a very high sensitivity, allowing for the detection of analyte concentrations in the $\mathrm{nM}$ range. Overall dimensions of the PN-CNT sensor used in this work could be scaled to accommodate the 
flow field dimensions of a microfluidic sensing device, allowing for the analysis of very small fluid volumes and providing an efficient method for chemical sensing. Moreover, the height, pore diameter and shape (porosity) of the microchannels within the CNT structures could be tailored for distinct sensing applications (e.g. high vs. low fluid flow environments, conjugation with biorecognition agents of distinct size/molecular weight within the CNT microchannels). Such further tuning of these microchannel CNT structures is reserved for future work.

\section{Acknowledgements}

The authors gratefully acknowledge financial support from Brigham Young University and equipment access from R. C. Davis and R. R. Vanfleet.

\section{References}

[1] J.P. Lopes, M.A. Alves, M.S.N. Oliveira, S.S.S. Cardoso, A.E. Rodrigues, Internal mass transfer enhancement in flow-through catalytic membranes, Chemical Engineering Science, 104 (2013) 1090-1106.

[2] M. Lyubovsky, H. Karim, P. Menacherry, S. Boorse, R. LaPierre, W.C. Pfefferle, et al., Complete and partial catalytic oxidation of methane over substrates with enhanced transport properties, Catalysis Today, 83 (2003) 183-197.

[3] A.T. Bell, H.P. Calis, T.S. Everwijn, A.W. Gerritsen, C.M. Van Den Bleek, F. Goudriaan, et al., Chemical Reaction Engineering: Science \& TechnologyMass transfer characteristics of parallel passage reactors, Chemical Engineering Science, 49 (1994) 4289-4297.

[4] A.W. Lodge, M.J. Lacey, M. Fitt, N. Garcia-Araez, J.R. Owen, Critical appraisal on the role of catalysts for the oxygen reduction reaction in lithium-oxygen batteries, Electrochimica Acta, 140 (2014) 168173.

[5] K. Qiu, Z.X. Guo, Hierarchically porous graphene sheets and graphitic carbon nitride intercalated composites for enhanced oxygen reduction reaction, Journal of Materials Chemistry A, 2 (2014) 3209-3215.

[6] S.B. Hall, E.A. Khudaish, A.L. Hart, Electrochemical oxidation of hydrogen peroxide at platinum electrodes. Part 1. An adsorption-controlled mechanism, Electrochimica Acta, 43 (1998) 579-588.

[7] A.A. Solovev, Y. Mei, E. Bermúdez Ureña, G. Huang, O.G. Schmidt, Catalytic Microtubular Jet Engines Self-Propelled by Accumulated Gas Bubbles, Small, 5 (2009) 1688-1692.

[8] L. Soler, V. Magdanz, V.M. Fomin, S. Sanchez, O.G. Schmidt, Self-Propelled Micromotors for Cleaning Polluted Water, ACS Nano, 7 (2013) 9611-9620.

[9] S. Sanchez, A.N. Ananth, V.M. Fomin, M. Viehrig, O.G. Schmidt, Superfast Motion of Catalytic Microjet Engines at Physiological Temperature, Journal of the American Chemical Society, 133 (2011) 14860-14863.

[10] R. Laocharoensuk, J. Burdick, J. Wang, Carbon-Nanotube-Induced Acceleration of Catalytic Nanomotors, ACS Nano, 2 (2008) 1069-1075.

[11] H. Ke, S. Ye, R.L. Carroll, K. Showalter, Motion Analysis of Self-Propelled Pt-Silica Particles in Hydrogen Peroxide Solutions, The Journal of Physical Chemistry A, 114 (2010) 5462-5467.

[12] S. Campuzano, J. Orozco, D. Kagan, M. Guix, W. Gao, S. Sattayasamitsathit, et al., Bacterial Isolation by Lectin-Modified Microengines, Nano Letters, 12 (2011) 396-401. 
[13] S. Sattayasamitsathit, Y. Gu, K. Kaufmann, W. Jia, X. Xiao, M. Rodriguez, et al., Highly Ordered Multilayered 3D Graphene Decorated with Metal Nanoparticles, Journal of Materials Chemistry A, 1 (2013) 1639-1645.

[14] Z. Chen, W. Ren, L. Gao, B. Liu, S. Pei, H.-M. Cheng, Three-dimensional flexible and conductive interconnected graphene networks grown by chemical vapour deposition, Nat Mater, 10 (2011) 424428.

[15] J.C. Claussen, A. Kumar, D.B. Jaroch, M.H. Khawaja, A.B. Hibbard, D.M. Porterfield, et al., Nanostructuring Platinum Nanoparticles on Multilayered Graphene Petal Nanosheets for Electrochemical Biosensing, Advanced Functional Materials, 22 (2012) 3399-3405.

[16] F. Meshkani, M. Rezaei, Nickel catalyst supported on magnesium oxide with high surface area and plate-like shape: A highly stable and active catalyst in methane reforming with carbon dioxide, Catalysis Communications, 12 (2011) 1046-1050.

[17] J.K. Bartley, C. Xu, R. Lloyd, D.I. Enache, D.W. Knight, G.J. Hutchings, Simple method to synthesize high surface area magnesium oxide and its use as a heterogeneous base catalyst, Applied Catalysis B: Environmental, 128 (2012) 31-38.

[18] M. Rezaei, M. Khajenoori, B. Nematollahi, Synthesis of high surface area nanocrystalline MgO by pluronic P123 triblock copolymer surfactant, Powder Technology, 205 (2011) 112-116.

[19] S. Hu, Y. Gong, Q. Xu, X. Liu, Q. Zhang, L. Zhang, et al., Highly selective formation of propylene from methanol over high-silica EU-1 zeolite catalyst, Catalysis Communications, 28 (2012) 95-99.

[20] P. Liu, J. Wang, R. Wei, X. Ren, X. Zhang, A Highly Efficient H $\beta$ Zeolite Supported Pt Catalyst Promoted by Chromium for the Hydroisomerization of n-Heptane, Catalysis Letters, 126 (2008) 346352.

[21] N. Parsafard, M.H. Peyrovi, M. Rashidzadeh, n-Heptane isomerization on a new kind of micro/mesoporous catalyst: Pt supported on HZSM-5/HMS, Microporous and Mesoporous Materials, 200 (2014) 190-198.

[22] T. Ginoza, K. Okamura, J. Fukuda, H. Suzuki, Improvement of detection sensitivity using electrodes with micropillar structures, Solid-State Sensors, Actuators and Microsystems Conference 2009 TRANSDUCERS 2009, pp. 1253-1256.

[23] M.-m. Guo, Y. Xia, W. Huang, Z. Li, Electrochemical fabrication of stalactite-like copper micropillar arrays via surface rebuilding for ultrasensitive nonenzymatic sensing of glucose, Electrochimica Acta, 151 (2015) 340-346.

[24] F. Schröper, D. Brüggemann, Y. Mourzina, B. Wolfrum, A. Offenhäusser, D. Mayer, Analyzing the electroactive surface of gold nanopillars by electrochemical methods for electrode miniaturization, Electrochimica Acta, 53 (2008) 6265-6272.

[25] P. Forrer, F. Schlottig, H. Siegenthaler, M. Textor, Electrochemical preparation and surface properties of gold nanowire arrays formed by the template technique, Journal of Applied Electrochemistry, 30 (2000) 533-541.

[26] R. Alkire, B. Gracon, Flow-Through Porous Electrodes, Journal of The Electrochemical Society, 122 (1975) 1594-1601.

[27] M. Paulin, D. Hutin, F. Coeuret, Theoretical and Experimental Study of Flow-Through Porous Electrodes, Journal of The Electrochemical Society, 124 (1977) 180-188.

[28] A.N. Strohl, D.J. Curran, Reticulated vitreous carbon flow-through electrodes, Analytical Chemistry, 51 (1979) 353-357.

[29] E. Csoeregi, L. Gorton, G. Marko-Varga, A.J. Tuedoes, W.T. Kok, Peroxidase-Modified Carbon Fiber Microelectrodes in Flow-Through Detection of Hydrogen Peroxide and Organic Peroxides, Analytical Chemistry, 66 (1994) 3604-3610.

[30] M. Khayyami, G. Johansson, D. Kriz, B. Xie, P.-O. Larsson, B. Danielsson, Flow-injection determination of trace hydrogen peroxide or glucose utilizing an amperometric biosensor based on glucose oxidase bound to a reticulated vitreous carbon electrode, Talanta, 43 (1996) 957-962.

[31] C. Gao, Z. Guo, J.-H. Liu, X.-J. Huang, The new age of carbon nanotubes: An updated review of functionalized carbon nanotubes in electrochemical sensors, Nanoscale, 4 (2012) 1948-1963. 
[32] M.H. Schnoor, C.D. Vecitis, Quantitative Examination of Aqueous Ferrocyanide Oxidation in a Carbon Nanotube Electrochemical Filter: Effects of Flow Rate, Ionic Strength, and Cathode Material, The Journal of Physical Chemistry C, 117 (2013) 2855-2867.

[33] A. Buffa, Y. Erel, D. Mandler, Carbon Nanotube Based Flow-Through Electrochemical Cell for Electroanalysis, Analytical Chemistry, 88 (2016) 11007-11015.

[34] K.M. Marr, B. Chen, E.J. Mootz, J. Geder, M. Pruessner, B.J. Melde, et al., High Aspect Ratio Carbon Nanotube Membranes Decorated with Pt Nanoparticle Urchins for Micro Underwater Vehicle Propulsion via H2O2 Decomposition, ACS Nano, 9 (2015) 7791-7803.

[35] B.V. Chikkaveeraiah, H. Liu, V. Mani, F. Papadimitrakopoulos, J.F. Rusling, A microfluidic electrochemical device for high sensitivity biosensing: Detection of nanomolar hydrogen peroxide, Electrochemistry Communications, 11 (2009) 819-822.

[36] A. Escarpa, M.C. González, M.A. López, A. Escarpa, M.C. González, M.Á. López, Electrochemical Sensing on Microfluidic Chips, Agricultural and Food Electroanalysis, John Wiley \& Sons, Ltd 2015, pp. 331-356.

[37] J.C. Claussen, I.L. Medintz, Using Nanotechnology to Improve Lab on a Chip Devices, Journal of Biochips \& Tissue Chips, 2 (2012) e117.

[38] L. Nyholm, Electrochemical techniques for lab-on-a-chip applications, Analyst, 130 (2005) 599-605.

[39] B. Chen, N.T. Garland, J. Geder, M. Pruessner, E. Mootz, A. Cargill, et al., Platinum Nanoparticle Decorated $\mathrm{SiO} 2$ Microfibers as Catalysts for Micro Unmanned Underwater Vehicle Propulsion, ACS Applied Materials \& Interfaces, 8 (2016) 30941-30947.

[40] J.C. Claussen, M.A. Daniele, J. Geder, M. Pruessner, A.J. Makinen, B.J. Melde, et al., Platinum-Paper Micromotors: An Urchin-Like Nanohybrid Catalyst for Green Monopropellant Bubble-Thrusters, ACS Applied Materials \& Interfaces, 6 (2014) 17837-17847.

[41] L. Qiang, S. Vaddiraju, J.F. Rusling, F. Papadimitrakopoulos, Highly sensitive and reusable Pt-black microfluidic electrodes for long-term electrochemical sensing, Biosensors and Bioelectronics, 26 (2010) 682-688.

[42] F. Sassa, H. Laghzali, J. Fukuda, H. Suzuki, Coulometric Detection of Components in Liquid Plugs by Microfabricated Flow Channel and Electrode Structures, Analytical Chemistry, 82 (2010) 87258732 .

[43] M.R. Guascito, D. Chirizzi, C. Malitesta, E. Mazzotta, M.Siciliano, T. Siciliano, et al., Low-potential sensitive $\mathrm{H} 2 \mathrm{O} 2$ detection based on composite micro tubular Te adsorbed on platinum electrode, Biosensors and Bioelectronics, 26 (2011) 3562-3569.

[44] X. Niu, H. Zhao, C. Chen, M. Lan, Platinum nanoparticle-decorated carbon nanotube clusters on screen-printed gold nanofilm electrode for enhanced electrocatalytic reduction of hydrogen peroxide, Electrochimica Acta, 65 (2012) 97-103.

[45] K.-J. Chen, C.-F. Lee, J. Rick, S.-H. Wang, C.-C. Liu, B.-J. Hwang, Fabrication and application of amperometric glucose biosensor based on a novel PtPd bimetallic nanoparticle decorated multiwalled carbon nanotube catalyst, Biosensors and Bioelectronics, 33 (2012) 75-81.

[46] Y. Fang, D. Zhang, X. Qin, Z. Miao, S. Takahashi, J.-i. Anzai, et al., A non-enzymatic hydrogen peroxide sensor based on poly(vinyl alcohol)-multiwalled carbon nanotubes-platinum nanoparticles hybrids modified glassy carbon electrode, Electrochimica Acta, 70 (2012) 266-271.

[47] L. Han, Q. Wang, S. Tricard, J. Liu, J. Fang, J. Zhao, et al., Amperometric detection of hydrogen peroxide utilizing synergistic action of cobalt hexacyanoferrate and carbon nanotubes chemically modified with platinum nanoparticles, RSC Advances, 3 (2013) 281-287.

[48] Z. Miao, D. Zhang, Q. Chen, Non-enzymatic Hydrogen Peroxide Sensors Based on Multi-wall Carbon Nanotube/Pt Nanoparticle Nanohybrids, Materials, 7 (2014) 2945.

[49] X. Li, X. Liu, W. Wang, L. Li, X. Lu, High loading Pt nanoparticles on functionalization of carbon nanotubes for fabricating nonenzyme hydrogen peroxide sensor, Biosensors and Bioelectronics, 59 (2014) 221-226. 
[50] H. Heli, N. Sattarahmady, R. Dehdari Vais, A.R. Mehdizadeh, Enhanced electrocatalytic reduction and highly sensitive nonenzymatic detection of hydrogen peroxide using platinum hierarchical nanoflowers, Sensors and Actuators B: Chemical, 192 (2014) 310-316.

[51] Y. Sun, K. He, Z. Zhang, A. Zhou, H. Duan, Real-time electrochemical detection of hydrogen peroxide secretion in live cells by $\mathrm{Pt}$ nanoparticles decorated graphene-carbon nanotube hybrid paper electrode, Biosensors and Bioelectronics, 68 (2015) 358-364.

[52] H. Mei, W. Wu, B. Yu, H. Wu, S. Wang, Q. Xia, Nonenzymatic electrochemical sensor based on Fe@Pt core-shell nanoparticles for hydrogen peroxide, glucose and formaldehyde, Sensors and Actuators B: Chemical, 223 (2016) 68-75.

[53] E. Atci, J.T. Babauta, H. Beyenal, A hydrogen peroxide microelectrode to use in bioelectrochemical systems, Sensors and Actuators B: Chemical, 226 (2016) 429-435. 